Goldschmidt 2021 Abstract

https://doi.org/10.7185/gold2021.5531

\title{
Saving Earth's Primitive Mantle
}

TIM D JONES ${ }^{1}$, PETER E. VAN KEKEN ${ }^{2}$ AND NATE

SIME $^{2}$

${ }^{1}$ University of California, San Diego

${ }^{2}$ Carnegie Institution for Science

Presenting Author: t6jones@ucsd.edu

Geochemical analyses reveal that some portion of the mantle has retained a chemically 'primitive' signature. How this material has survived vigorous convection over Earth's lifetime is an open question. Here we propose that it may be preserved at the base of the mantle in large accumulations of subducted lithosphere. These accumulations are dominated by dense oceanic crust but can comprise up to $30 \%$ primitive material. The intermingling of oceanic crust and primitive material may explain why the chemical signatures of both coexist in volcanic eruptions at Earth's surface.

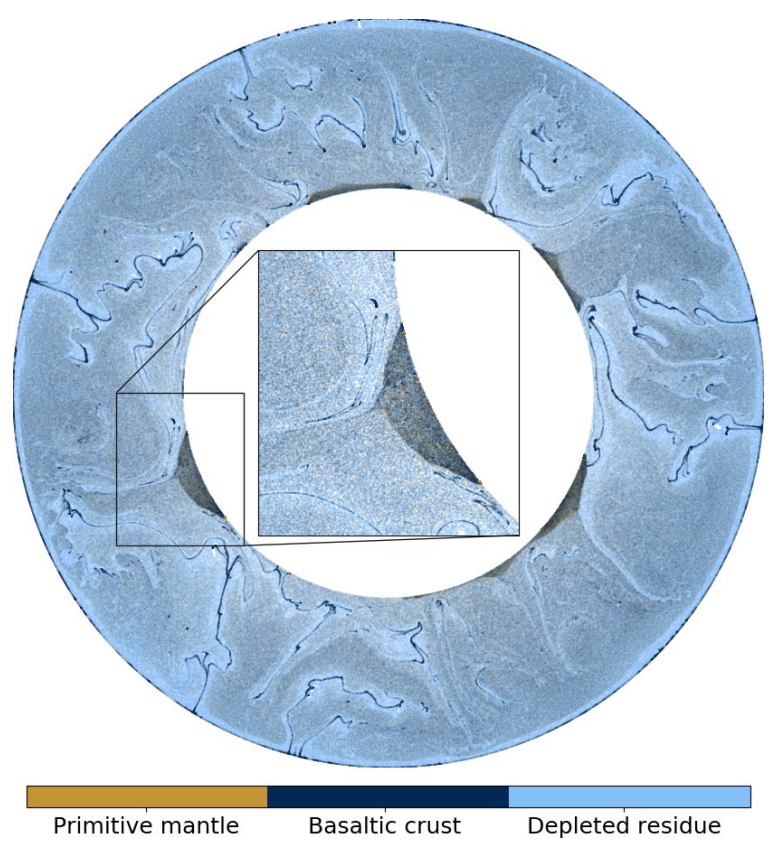

